\title{
Low molecular weight heparins (enoxaparin) in the management of unstable angina: the TIMI studies
}

\author{
E Gurfinkel, B M Scirica
}

During the 1980s, results from the first large scale clinical studies on acute coronary syndrome were rapidly translated into clinical application. ${ }^{1}$ The development of effective antithrombotic medication brought a significant reduction in morbidity and mortality. However, despite the data showing that new antithrombotic agents such as low molecular weight heparins (LMWHs) offered advantages over placebo, questions remained about how these new drugs compared to each other. Continued improvements in the "standard of care" for acute coronary syndromes, as well as the economic changes in clinical research, have greatly complicated not only the design and execution of large clinical trials studying these new agents, but also the comparability. ${ }^{2}$ Subtle differences in inclusion and exclusion criteria and in definitions of end points require great caution when interpreting the results.

In spite of these difficulties, the recent clinical trials with LMWHs provide valuable information about the clinical course of unstable angina and allow us to consider this syndrome in a new light. The onset of unstable angina appears to be the precise moment of transition from stable state to non-Q wave myocardial infarction (MI) or $Q$ wave MI. Increasingly sensitive methods of detecting myocardial necrosis, combined with ECG changes, offer the opportunity that in due course acute coronary syndromes will become divided into two groups- $Q$ wave infarct or non- $Q$ wave infarct - and it may mean that unstable angina as a final diagnosis becomes redundant. We describe here the design and results of the LMWH studies, and in particular the TIMI $11 \mathrm{~A}$ and $\mathrm{B}$ trials, and the changes in treatment strategies evolving from these trials.

\section{LMWHs and unstable angina}

The rationale for using LMWHs in arterial thrombosis is based on their structural and chemical features. The most important of these is the small size of LMWHs in relation to unfractionated heparin (UFH). LMWHs inhibit factor $\mathrm{Xa}$ and thrombin (factor IIa) to a lesser extent, giving an anti Xa:anti IIa ratio varying from $4: 1$ to $2: 1$ for the different LMWHs, compared to the 1:1 ratio of UFH. LMWHs are also resistant to inhibition by activated platelets and bind to a lesser extent than UFH to proteins, resulting in a bioavailability approaching $100 \%$, a longer half life, a dose dependent response, and a more predictable anticoagulant effect which precludes the need for laboratory monitoring. ${ }^{3}$ In addition,
LMWHs may offer a potential antiinflammatory effect, ${ }^{4}$ which has become an important consideration because of the recent findings of the mechanism of atherosclerotic injury.

The first study using LMWH enrolled 219 patients with a preliminary diagnosis of unstable angina who had experienced their most recent rest pain within 24 hours of admission. ${ }^{5}$ Group A received oral aspirin and subcutaneous nadroparin, 214 units Institute Choay (UIC) every 12 hours. Patients in group B were treated with oral aspirin and a bolus of UFH 5000 IU followed by a continuous infusion of $400 \mathrm{IU} / \mathrm{kg} /$ day, determined by a nomogram. Group C was treated with aspirin and placebo. The group treated with nadroparin experienced a significant reduction of ischaemic events and complications (22\% complications in the nadroparin group versus $66 \%$ with $\mathrm{UFH}$ and $59 \%$ with the aspirin group).

This relatively small trial led the way for three subsequent trials. The FRISC trial compared subcutaneous dalteparin at a dose of $120 \mathrm{IU} / \mathrm{kg}$ twice daily (together with aspirin) against placebo and aspirin in a group of 1500 patients with unstable coronary artery disease. ${ }^{6}$ Results from recent studies showed a continued prothrombotic state in patients after the acute event, ${ }^{7}$ therefore the FRISC trial included patients who had experienced an anginal event up to 72 hours before admission. After six days there was a $48 \%$ reduction of deaths and recurrent non-fatal myocardial infarctions in the group treated with dalteparin and aspirin compared with aspirin alone $(1.8 \%$ $v 4.7 \%, \mathrm{p}<0.001)$. The results of this study support the hypothesis that the thrombotic state may continue during the quiescent phase of angina. ${ }^{8}$ This may be responsible for the substantial number of recurrent ischaemic events, which could be prevented with continued antithrombotic treatment.

The FRIC trial compared dalteparin in the same dose as the FRISC trial with standard

Trial acronyms
ESSENCE: Efficacy and Safety of Sub-
cutaneous Enoxaparin in Non-Q-wave Cor-
onary Events
FRIC: FRagmin In unstable Coronary
artery disease
FRISC: FRagmin during InStability in
Coronary artery disease
TIMI: Thrombolysis In Myocardial Infarc-
tion


UFH treatment in 1482 patients. ${ }^{9}$ All patients were also treated with aspirin. Treatment was continued for six days and into the outpatient stage. This study showed equivalent efficacy for dalteparin and UFH, with no significant difference in the rate of ischaemic events $(9.3 \% v$ $7.8 \%, p=0.42)$. Even though this study did not show an advantage in the use of dalteparin compared to $\mathrm{UFH},{ }^{10}$ it was responsible for a conceptual change in treatment strategies to extend treatment to cover the ongoing thrombotic state.

The ESSENCE trial was the first trial to compare a different LMWH, enoxaparin ( $1 \mathrm{mg} / \mathrm{kg}$ subcutaneously every 12 hours), with standard UFH treatment both combined with aspirin, in patients admitted with unstable angina or non-Q wave MI. ${ }^{11}$ The study enrolled 3171 patients and showed a significant reduction in the composite end point (death, MI, or recurrent angina) in favour of the enoxaparin group at 14 days after admission $(16.6 \% v$ $19.8 \%, \mathrm{p}=0.019)$, and at 30 days after admission when compared to the UFH group $(19.8 \% v 23.3 \%, \mathrm{p}=0.017)$. This reduction was maintained at one year follow up. In addition, the enoxaparin group had a reduced requirement for diagnostic catheterisations and revascularisation.

LMWHs differ from each other in a number of characteristics, including molecular weight, bioavailability, and their anti $\mathrm{Xa}$ activity. These pharmacological differences may explain the inconsistencies in clinical outcomes observed in trials. Recently it has also been suggested that LMWHs may differ in other antithrombotic potencies such as their tissue factor pathway inhibitor releasing abilities and their ability to inhibit platelet activation by von Willebrand's factor. ${ }^{12}$ The overall antithrombotic activity of LMWHs with similar anti Xa activity such as nadroparin and enoxaparin may therefore vary considerably. The promising results of the ESSENCE trial which adopted the use of the LMWH enoxaparin prompted further research into its antithrombotic efficacy in the TIMI 11 studies.

\section{TIMI 11 studies}

The TIMI 11 studies comprised two phases. The first, TIMI $11 \mathrm{~A},{ }^{13}$ was a dose ranging trial of enoxaparin, while TIMI 11B examined efficacy and safety of long term use of enoxaparin in both the active and the quiescent phases of non-Q wave syndromes, when it is assumed that the prothrombotic state is still present.

TIMI $11 \mathrm{~A}$ was a multicentre trial comparing two weight adjusted doses of subcutaneous enoxaparin in patients with unstable angina or non-Q wave MI. All patients received two weeks of treatment, starting with an initial intravenous bolus of $30 \mathrm{mg}$ of enoxaparin followed by weight adjusted subcutaneous injections $(1.25 \mathrm{mg} / \mathrm{kg}$ every 12 hours or $1.0 \mathrm{mg} / \mathrm{kg}$ every 12 hours). Following hospital discharge, patients received fixed dose subcutaneous injections of $60 \mathrm{mg}$ twice daily for patients weighing $\geqslant 65 \mathrm{~kg}$ and $40 \mathrm{mg}$ twice daily for patients $<65 \mathrm{~kg}$. A significant difference in the incidence of major bleeding was observed between the $1.0 \mathrm{mg} / \mathrm{kg}$ regimen $(1.9 \%)$ and the $1.25 \mathrm{mg} / \mathrm{kg}$ regimen $(6.5 \%)$. There was no difference between the two doses of enoxaparin in the prevention of death, recurrent MI, or the need for revascularisation, and there was no evidence of a rebound increase in ischaemic events after treatment ended. It was therefore concluded that a dose of $1.0 \mathrm{mg} / \mathrm{kg}$ enoxaparin is the preferred dose.

The TIMI $11 \mathrm{~B}$ trial is a multicentre, randomised, double blind, parallel group trial with an enrolment goal of 4000 patients. Patients with unstable angina and non- $Q$ wave MI, with pain at rest lasting longer than five minutes within the previous 24 hours and ST segment deviation, were eligible for inclusion. Patients were randomised to receive enoxaparin, $30 \mathrm{mg}$ intravenous bolus followed by subcutaneous injections of $1.0 \mathrm{mg} / \mathrm{kg}$ twice daily for at least 72 hours, or standard UFH treatment. The chronic phase compared enoxaparin (40 mg twice daily for patients $<65 \mathrm{~kg}$ and $60 \mathrm{mg}$ twice daily for patients $\geqslant 65 \mathrm{~kg}$ ) versus placebo injections for 43 days.

The primary objective of the acute phase of TIMI 11B was to show at least equivalent efficacy between enoxaparin and UFH in preventing major clinical events. The chronic phase was designed to evaluate whether there was any additional beneficial effect of continued enoxaparin treatment beyond the acute phase. The preliminary results of the TIMI $11 \mathrm{~B}$ trial suggest that enoxaparin is more effective than UFH in the treatment of unstable angina, confirming the results of the ESSENCE trial. ${ }^{11}$

\section{Conclusion}

LMWHs have been shown to have several advantages over the use of standard UFH in terms of ease of use, pharmacological properties, and clinical outcomes. The clinical trials carried out to date and experimental data suggest that there are important differences between LMWHs in terms of bioavailability and biological activity. In the ESSENCE trial the LMWH enoxaparin was shown to reduce morbidity and mortality outcomes significantly compared to UFH. ${ }^{11}$ The TIMI $11 \mathrm{~B}$ study was designed to confirm the results of the ESSENCE trial and to investigate the effect of prolonged use of LMWH beyond the acute phase of unstable angina. Confirmation of the results of the ESSENCE trial would support the standard use of the LMWH enoxaparin in the management of non- $Q$ wave coronary syndromes.

1 Cannon CP, Braunwald E, McCabe C, et al. The hrombolysis in myocardial infarction (TIMI) trials: the first decade. F Intervent Cardiol 1995;8:117-35.

2 TIMI IIIB Investigators. Effects of tissue plasminogen activator and a comparison of early invasive and conservative strategies in unstable angina and non-Q-wave myocardial infarction: results of the TIMI IIIB trial. Circulation 1994: 89:1545-56.

3 Fareed J, Hoppensteadt DA. Pharmacology of the lowmolecular-weight heparins. Semin Thromb Hemost 1996;22: 13-18.

4 Bozovich G, Gurfinkel E, Mautner B, et al. Free tissue factor pathway inhibitor is elevated in patients with acute nonQ-wave coronary syndromes. F Am Coll Cardiol 1998; 31(suppl C):C99. 
5 Gurfinkel E, Manos E, Mejaíl R, et al. Low molecular weight heparin versus regular heparin or aspirin in the treatment of unstable angina.

6 FRISC Study Group. Low molecular weight heparin during instability in coronary artery disease: Fragmin during instability in coronary artery disease. Lancet 1996;347:5618.

7 Gurfinkel E, Altman R, Rouvier J, et al. Significance of thrombosis and thrombolysis in silent myocardial ischaemia. Br Heart f 1994;71:151-5.

8 Merlini P, Bauer K, Oltrona L, et al. Persistent activation of coagulation mechanism in unstable angina and myocardial infarction. Circulation 1994;90:61-8.

9 Klein W, Buchwald A, Hillis SE, et al. Low molecular weight heparin (dalteparin) in the management of unstable coronary artery disease (FRIC). Circulation 1997;96:61-8.
10 Gurfinkel E, Fareed J, Antman E, et al. The rationale for the management of coronary syndromes with low molecular weight heparins. Am f Cardiol 1998;82(suppl 5B):15L$18 \mathrm{~L}$.

11 Cohen M, Demers C, Gurfinkel EP, for the ESSENCE Study Group. A comparison of low-molecular-weight heparin with unfractionated heparin for unstable coronary artery disease: efficacy and safety of subcutaneous enoxaparin in non-Q-wave coronary events study group. $N$ Engl parin in non-Q-wave coron
$\mathfrak{f}$ Med 1997;337:447-52.

12 Fareed J, Jeske W, Hoppensteadt D, et al. Low-molecularweight heparins: pharmacologic profile and product differentiation. Am f Cardiol 1998;82(suppl 5B):3L-10L.

13 Antman EM. Dose-ranging trial of enoxaparin for unstable angina: results of TIMI 11A. F Am Coll Cardiol 1997;29: $1474-82$. 